\title{
Enzymatic synthesis of long double-stranded DNA labeled with haloderivatives of nucleobases in a precisely pre-determined sequence
}

Ireneusz Sobolewski, Katarzyna Polska, Agnieszka Żylicz-Stachula, Joanna Jeżewska-Frąckowiak, Janusz Rak and Piotr Skowron ${ }^{*}$

\begin{abstract}
Background: Restriction endonucleases are widely applied in recombinant DNA technology. Among them, enzymes of class IIS, which cleave DNA beyond recognition sites, are especially useful. We use Bsal enzyme for the pinpoint introduction of halogen nucleobases into DNA. This has been done for the purpose of anticancer radioand phototherapy that is our long-term objective.

Results: An enzymatic method for synthesizing long double-stranded DNA labeled with the halogen derivatives of nucleobases (Hal-NBs) with 1-bp accuracy has been put forward and successfully tested on three different DNA fragments containing the 5-bromouracil (5-BrU) residue. The protocol assumes enzymatic cleavage of two Polymerase-Chain-Reaction (PCR) fragments containing two recognition sequences for the same or different class IIS restriction endonucleases, where each PCR fragment has a partially complementary cleavage site. These sites are introduced using synthetic DNA primers or are naturally present in the sequence used. The cleavage sites are not compatible, and therefore not susceptible to ligation until they are partially filled with a Hal-NB or original nucleobase, resulting in complementary cohesive end formation. Ligation of these fragments ultimately leads to the required Hal-NB-labeled DNA duplex. With this approach, a synthetic, extremely long DNA fragment can be obtained by means of a multiple assembly reaction ( $\times$ maximum PCR product length: $n \times$ app. $50 \mathrm{~kb}$ ).

Conclusions: The long, precisely labeled DNA duplexes obtained behave in very much the same manner as natural DNA and are beyond the range of chemical synthesis. Moreover, the conditions of synthesis closely resemble the natural ones, and all the artifacts accompanying the chemical synthesis of DNA are thus eliminated. The approach proposed seems to be completely general and could be used to label DNA at multiple predetermined sites and with halogen derivatives of any nucleobase. Access to DNAs labeled with Hal-NBs at specific position is an indispensable condition for the understanding and optimization of DNA photo- and radiodegradation, which are prerequisites for clinical trials of Hal-NBs in anticancer therapy.
\end{abstract}

\section{Background}

Class IIS restriction endonucleases (REases) are widely applied in recombinant DNA technology. In a series of pioneer studies, Szybalski et al. [1] showed that class-IIS REases offer novel possibilities for DNA manipulation, for example, a "universal restriction endonuclease", cleaving a pre-determined sequence in single-stranded DNA with the assistance, inter alia, of hairpin

\footnotetext{
* Correspondence: skowronp@chem.univ.gda.pl
Department of Chemistry University of Gdańsk, Sobieskiego 18, 80-952

* Correspondence: skowronp@chem.univ.gda.pl
Department of Chemistry University of Gdańsk, Sobieskiego 18, 80-952 Gdańsk, Poland
}

(c) 2011 Sobolewski et al; licensee BioMed Central Ltd. This is an Open Access article distributed under the terms of the Creative Commons Attribution License (http://creativecommons.org/licenses/by/2.0), which permits unrestricted use, distribution, and reproduction in any medium, provided the original work is properly cited. oligodeoxyribonucleotides (oligo) [2,3], Achilles' Heel Cleavage of DNA $[4,5]$, a DNA fragment amplification vector [6], and chimeric repressor-REase enzymes [7]. Here we use class IIS enzymes to precisely incorporate modified nucleobases into DNA in order to enhance its photo- and radiosensitivity.

Substituting a hydrogen atom of a nucleic base (NB) with a halogen atom leads to a minor change in the NB structure. As a result, DNA containing halogen-substituted nucleobases (Hal-NBs) possesses the same structural features as the native biopolymer. Owing to the photo- and radiosensitivity of Hal-NB, however, such 
modified DNA becomes more susceptible to damage by ionizing radiation and more sensitive to UV light. Therefore, halogen-substituted uracils (5-XU) have been used in the past as structural probes of the nucleic acid structure [8-10] and for mapping protein-nucleic acid interactions [11-14]. 5-bromouracil (5-BrU) has also been employed in studies of long-distance electron transfer in DNA [15]. The attachment of an electron to 5 - BrU triggers the quantitative release of bromide anions and uracil, a process that is easily evaluated. Since the number of $5-\mathrm{BrU} /$ electron reactions can be monitored, the maximum average electron migration distance along the helix can be estimated [16]. Recently, Cecchini et al. [17] demonstrated that the irradiation of double-stranded DNA containing 5-BrU with ionizing radiation leads to interstrand cross-links, one of the most toxic types of DNA damage. The toxicity of DNA cross-links is probably the result of two mechanisms: one prevents strand separation, thus inhibiting both transcription and replication, the other can induce mutations and DNA rearrangements as a result of the repair process [17]. It has also been shown that irradiation of 5-bromocytosine (5-BrC) [18-20] labeled DNA with near-UV light brings about intrastrand photocross-linking: adducts are formed photochemically between $5-\mathrm{BrC}$ and adjacent nucleobases.

Incorporation of 5-BrU in DNA increases the biopolymer's susceptibility to single- and double-strand breakage induced by ionizing radiation [21] and influences the rate of DNA repair of potentially lethal damage [22]. Among the main products of water radiolysis are lowenergy electrons that can attach to bromouracil [17]. The unstable bromouracil anion is stabilized when the bromine anion is detached, which causes the very reactive uracil-5-yl radical to form. This species can attack the $\mathrm{C} 2$ ' and $\mathrm{C} 1$ ' centers of the adjacent 2-deoxyribose, thereby inducing DNA strand cleavage. It is also assumed that the same uridyl radical forms as a result of interaction between UV-radiation and DNA labeled with 5-bromouracil [23,27]. The preliminary steps of the photochemical process are probably related to photoinduced electron transfer between electronically excited 5 -bromouracil and the adjacent nucleobase $[25,26]$. This conclusion was suggested by the experimentally observed strong dependence of the extent of damage on the base sequence [27-29].

Since the structural changes associated with the incorporation of a halogen atom into a nucleic acid base are only minor, nucleotides containing Hal-NBs can be used by a cell for DNA biosynthesis (the cellular enzymatic system does not radically differentiate between Hal-NBs and natural nucleotides) [30]. Furthermore, the incorporation of Hal-NBs in DNA sensitizes the biopolymer to $\mathrm{UV}$ and ionizing radiation. It seems, therefore, that Hal-
NBs could be employed in the therapy of cancer diseases. It has already been reported that 5 - $\mathrm{BrU}$ increases the likelihood of cells being damaged by ionizing radiation [31]. The enhanced response of non-hypoxic tumor cells to radiation in the presence of bromodeoxyuridine, iododeoxyuridine and fluorodeoxyuridine has been recognized in several clinical trials [32-34]. Some clinical studies have also reported the radiosensitization of malignant brain tumors by bromodeoxyuridine [35].

With such properties, Hal-NBs are potentially potent anticancer drugs in radio- and phototherapy. However, without an understanding of the molecular mechanisms leading to DNA breakage their rational use is not possible. Hence, before these substances can be implemented in clinical practice, comprehensive, multidisciplinary studies need to be carried out in order to elucidate the consecutive stages of the process leading to DNA damage induced by UV light or an excess electron.

If the photo- and radiochemical studies aiming at the understanding and optimization of DNA degradation process are to yield reliable results, we need access to DNA fragments of pre-defined sequences labeled with Hal-NBs at precisely determined positions. Furthermore, relatively short double-stranded DNA (from tens to hundreds of base pairs) is known to behave more like a "rigid rod" [36]. On the other hand, DNA molecules in vivo achieve lengths of from several thousand to hundreds of millions of base pairs. Hence, short synthetic DNA fragments seem to be quite a crude model of natural DNA, since the effects due to folding (e.g. supercoiled DNA) could profoundly affect the susceptibility to damage of the biopolymer's chemical bonds. So far, all studies of damage to Hal-NB-labeled DNA have focused on short oligo fragments - 30-40 base-pairs (bp) at the most. In this work we describe a new technique of DNA labeling for synthesizing DNA fragments of up to several hundred base pairs. This target has been achieved by employing the site-directed introduction of nucleotide derivatives into dsDNA molecules with the use of a multi-enzymatic complex. Such long DNA duplexes behave in a manner similar to that of natural DNA and are beyond the range of efficient chemical synthesis. Moreover, bacterial thermostable polymerases are employed in DNA synthesis; consequently, the conditions of DNA synthesis closely resemble the natural ones, and artifacts accompanying chemical synthesis (impurities resulting from side-products, uncontrolled modifications, heterogeneity of DNA length, etc.) are thus eliminated. Although the nature of these trace contaminants has not been evaluated, gene cloning scientists are well aware that synthetic DNA tends to cause far greater problems in enzymatic manipulation than DNA obtained from a native source or in a PCR reaction. This also applies to ligation efficiency. 
In the following we present details of the method specially designed to prepare long DNA duplexes labeled with Hal-NBs.

\section{Results and discussion General idea}

The incorporation of one or two molecules of 5 -BrdU per molecule of synthetic duplex taking place in the above-mentioned process is illustrated schematically in Figure 1. Let us assume that two double-stranded DNA fragments (I-T and III-Br, Figure $1 \mathrm{C}$ ) possessing 3 -nt complementary sticky ends are available. One of these fragments (III-Br) contains 5-BrdU instead of thymidine in the base pair preceding the cohesive end. After the ligation of I-Br with III-T, the final product is synthesized, i.e. double-stranded DNA internally labeled with 5-BrdU. I-T and III-Br can be obtained from fragments I and III (Figure 1C) using a DNA polymerase and dTTP or BrdUTP, respectively. The first base of the initially non-complementary 4-nt cohesive ends of fragments I and III has to be adenine if a DNA fragment labeled with 5 -BrdU is to be synthesized. The filling of the non-complementary strand with thymidine or 5-bromouridine (single- or double labeling of both strands) produces two complementary, 3-nt sticky ends. If, for instance, the 5'-YYY sequence (the lower strand of the final product) appears at the cohesive end of III-Br, the 5 -XXX sequence (the upper strand of the final product) has to be generated in I-T, where $\mathrm{X}$ and $\mathrm{Y}$ are the complementary bases. Thus, the 4-nt cohesive ends generated by a class-IIS REase cannot be cross-ligated between duplexes I and III unless the first base of the 4-nt cohesive end is filled with dTTP (or BrdUTP) (Figure 1D).

So, in order to obtain a DNA fragment with 5 -BrdU incorporated into it, two double stranded duplexes (PCR1 and PCR2, Figure 1AB) have to be synthesized with appropriately located terminal sites sensitive to class-IIS REases. These duplexes are then used to generate sub-duplexes by BsaI digestion, yielding four fragments: I, II, III, and IV. Filling duplexes I and III with BrdUTP (resulting in I-Br and III-Br, Figure $1 \mathrm{C}$ ) yields an internally double labeled DNA molecule containing two BrdU residues separated by $3 \mathrm{bp}$.

In principle, the same or different class-IIS REases, producing 5' protruding 4-nt cohesive ends, could be used for the cleavage of PCR1 and PCR2. After minor modification, also other class-IIS REases producing $5^{\prime}$ protruding cohesive ends of the length 2-nt or longer can be used. The choice of class-IIS REase used will also be dictated by the preferred absence of its cognate site within the DNA segment to be amplified as well as by its desired enzymatic parameters. However, the presence of the same class-IIS site within the DNA molecule does not preclude application of the method. Statistically only 1 in 2564 -nt cohesive ends in the cleavage site will be identical. Because of the uniqueness of cohesive ends generated by class-IIS REases, only intended hybrid molecules should be assembled. However, if the cohesive ends have consecutive adenines (Figure 2; in the seventh $(\mathrm{X})$ and ninth $(\mathrm{Y})$ position) resulting ends will not be able to ligate after filing them with BrdUTP. In case of a singly labeled DNA, on average 1 in 4 of 4-bp cleavage sites sequences will block the assembly reaction. Hence, for the 6-bp class IIS REase recognition site (on average one every $4096 \mathrm{bp}$ ), flanked by 4-bp cleavage site, the maximum length of the final labeled molecule is limited to the assembly of 3 permissive combinations (C, G or $\mathrm{T}$ in the crucial position). Thus the maximum length of the labeled DNA molecule amounts to $4096 \times 3=12$ $288 \mathrm{bp}$. In order to overcome limitation imposed by the presence of the internal recognition sites one may select those REases, which recognize longer DNA sequences. For example, SapI REase recognizes 7-bp sequence: GCTCTTC(N1/4), thus cleaving on average every 16 $384 \mathrm{bp}$ [37]. Another solution of the problem could be the 2-step methylation method for extension of a recognition site of a class-IIS REases [38].

There are two alternative modes of assembling hybrid DNA molecules. In the first mode, native sequence hybrid DNA molecules are generated when class-IIS sites are oriented toward the 3' ends of the primers used and are adjacent to the beginning of the original, native sequence to be re-joined. 5 ' portions of the primers along with the class-IIS sites are cut off during the procedure, leaving only 4-nt cohesive ends, which are part of the original DNA template (Figure 2). When the natural sequences are to be labeled, they must be in the form of 5'-TXXXN-3', where the first X cannot be T and $\mathrm{N}$ cannot be identical to the last $\mathrm{X}$ (in the single position labeling variant) or the sequence must be in the form of 5'-TXXXA-3', where the first X cannot be T and the last X cannot be A (in the double position labeling variant). The bases in the 7-9 positions (marked as $\mathrm{Xs}$ ) do not have to be identical (Figure 2A). It is important to remember during primers design, that incorporated class-IIS REase sites need to be properly positioned, e.g. offset by one base in the two primers to give 5'-XXXA (or 5'-XXXN for single labeling variant) and 5'-YYYA overhangs, to avoid incorporation of an additional base into the native sequence (Figure 2D).

The second mode is based on either the 5'- or the 3'orientation of the class-IIS REase sites, where additional sequences are incorporated from the primers used (with or without the class-IIS sites used) (Figure 1). Should additional sequences be incorporated, the procedure will result in internally labeled mutant hybrid molecules. The potential applicability extends beyond an 


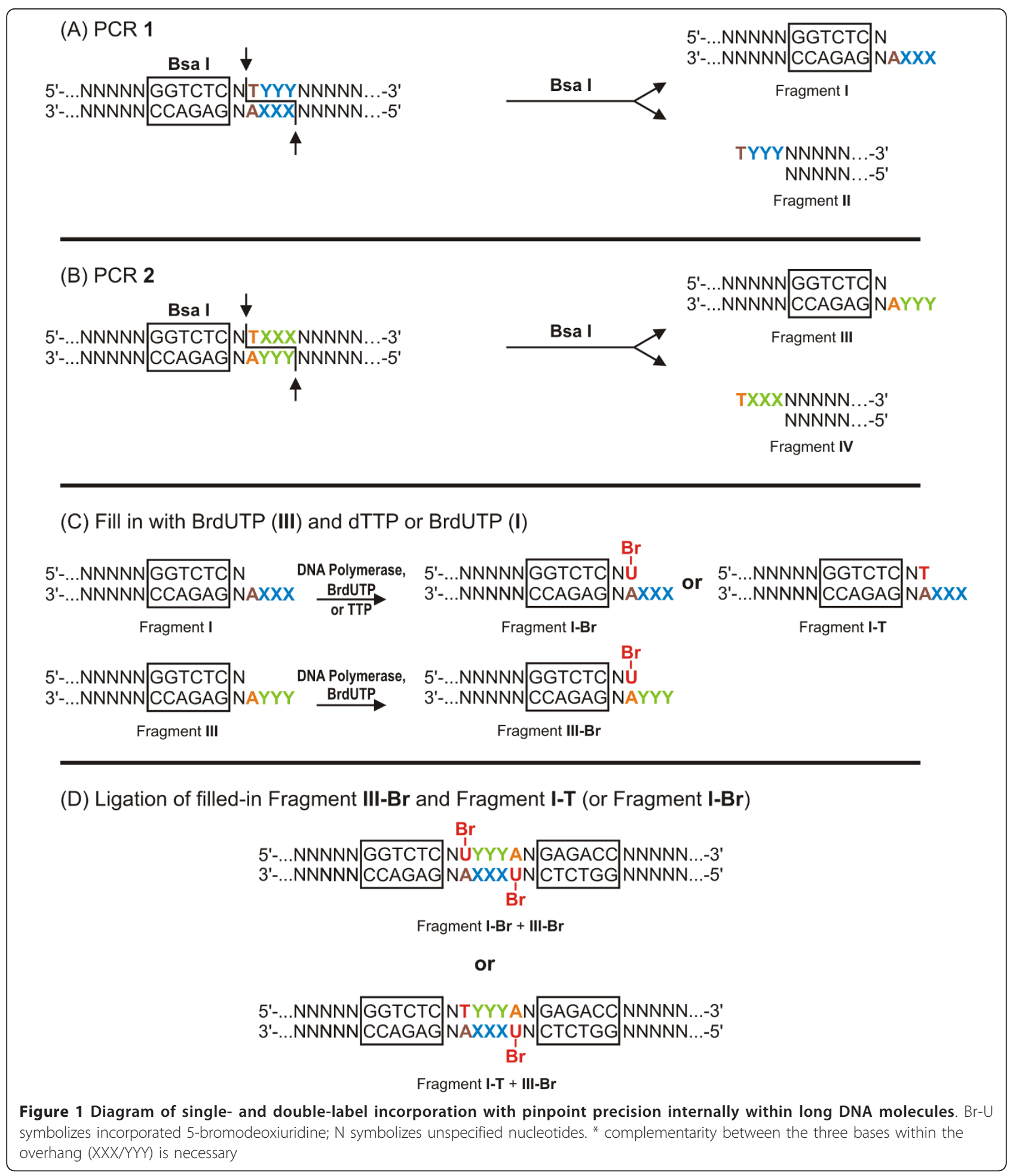

incorporation of Hal-Nbs for DNA damage studies, but can be used to study protein-DNA interaction by, for example, the precise incorporation of modified bases into the DNA-interacting protein recognition sites present on long DNA molecules.
Design of hybrid, BrdU-labeled DNA molecules with the use of Bsal REase

A specific class-IIS enzyme BsaI recognizes 5'GGTCTC-3' DNA sequence and cleaves downstream at $1 \mathrm{nt}$ (top strand) and $5 \mathrm{nt}$ (bottom strand) at any 
(A) Native DNA

$123456 \quad 789101112131415$

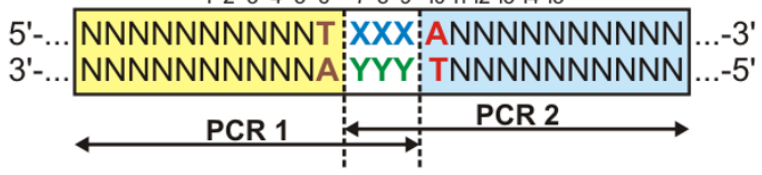

(B) PCR 1

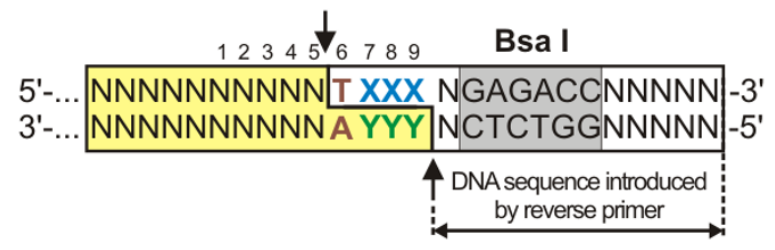

(C) PCR 2

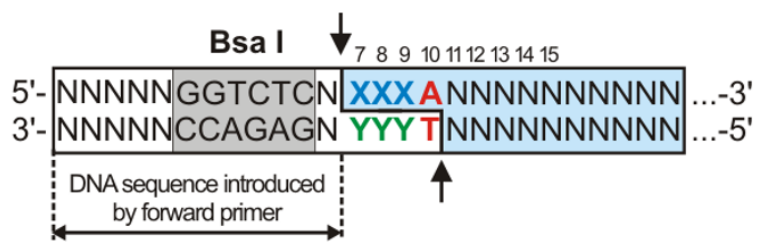

(D) Internally labeled native DNA molecule after ligation of filled-in fragments

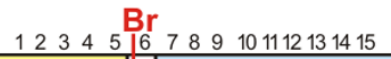

5 -'... NNNNNNNNNNUXXX ANNNNNNNNNN ...-3'

$3 '-. .$. NNNNNNNNNNA YYY $\mid$ T NNNNNNNNNN ...-5'

single labeling mode

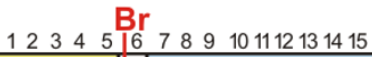

5'-... NNNNNNNNNNU]XXX ANNNNNNNNNN ...-3'

or $\quad 3^{\prime}-\ldots$ NNNNNNNNNNA YYY UNNNNNNNNNN $\ldots-5^{\prime}$

$\mathrm{Br}$

double labeling mode

Figure 2 Diagram of internally labeled native-sequence hybrid DNA molecule generation. To obtain a labeled native DNA sequence the following sequence requirements must be fulfilled: * in the seventh $(X)$ and/or ninth position $(Y)$ a non-A nucleotide is required depending on the labeling mode. ${ }^{*}$ complementarity between the three bases within the overhang (positions 7-9; XXX/YYY) is necessary. ${ }^{*} \mathrm{~A} / \mathrm{T}$ in the tenth position is not required for a single DNA labeling. Br-U symbolizes incorporated 5-bromodeoxiuridine; $N$ symbolizes unspecified nucleotides

sequence, leaving complementary "sticky" ends. BsaI was selected for this study as it recognizes DNA relatively infrequently - on average every 4096 bp, cleaves DNA to completion and is a robust thermophilic enzyme. Processing duplexes with the enzyme generates two fragments, I and II, for the first duplex (PCR 1), and two fragments, III and IV, for the second one (PCR 2) (Figure $1 \mathrm{AB}$ ). Since both double-stranded duplexes possess the class-IIS REase (BsaI) site, the tetranucleotide "sticky" ends produced by BsaI cleavage can be pre-programmed to have any sequence. The sequence of the cohesive ends has been devised in such a way that the first base, immediately adjacent to the double stranded portion of the DNA fragment (thus closest to the classIIS BsaI recognition site), is the same for both the first and the second duplex (in the case of BrdU incorporation, it is the complementary base A), whereas the following 3-nt are reverse complements: 5'-GGG and 5'CCC. Thus, the cohesive ends generated by BsaI are 5'GGGA and 5'-TCCC for duplex 1, and 5'-CCCA and 5'TGGG for duplex 2. Hence, the cohesive ends generated cannot be cross-ligated between duplexes 1 and 2 unless the first base of the 4-nt cohesive end is filled with dTTP (or BrdUTP), generating complementary 5'-CCC and 5'-GGG single stranded DNA sequences (Figure 1C). Cleaved PCR fragments not filled with BrU are 
effectively excluded from the ligation reaction, as no compatible cohesive ends are produced. Thus, to activate the final step, the missing thymidine in fragment III needs to be complemented with BrdU and the missing thymidine (or BrdU for the purpose of double labeling) in fragment I. Ligation of fragments I and III produces the new double stranded duplex, containing one or two precisely incorporated internal BrdU residues (Figure 1D). In general, the procedure can be extended, so that in one production cycle duplexes can be prepared with several different specific sequences cleaved by different enzymes, incorporating a label at more than one predefined location or incorporating different labels in the same DNA molecule. We chose 5'-CCC/5'-GGG cohesive ends to increase annealing, and therefore to achieve more efficient ligation. Nevertheless, the method is universally applicable to any asymmetric cohesive ends, as long as complementarity is generated upon partial filling. The mutations accumulating in the PCR step of preparing DNA to be modified may constitute a limitation to the method if an excessive number of cycles is being used. It would therefore be beneficial to optimize every labeling reaction at the initial PCR stage as well, in order to minimize the effective number of cycles needed. The polymerase used imposes a limitation on a modified nucleotide incorporated into DNA. Every polymerase/label combination therefore needs to be verified experimentally.

\section{Assessing various DNA polymerases and assembly reaction conditions for the ability to incorporate BrdU}

The method described here was used as a model for further anti-cancer therapy studies; it was not limited to the use of BrdUTP as a cytotoxic compound when incorporated into DNA. It is expected that the different labels present in modified dNTPs will be utilized with various affinities by DNA Polymerases, thus resulting in incorporation into DNA with greatly varying efficiency. Reaction limitations may also arise from the substrate requirements of DNA Ligase. Figure 3 shows labeling reactions performed under demanding conditions - double BrdU residues incorporated in close proximity using various DNA polymerases. The conditions of double labeling were chosen to determine whether DNA Ligase

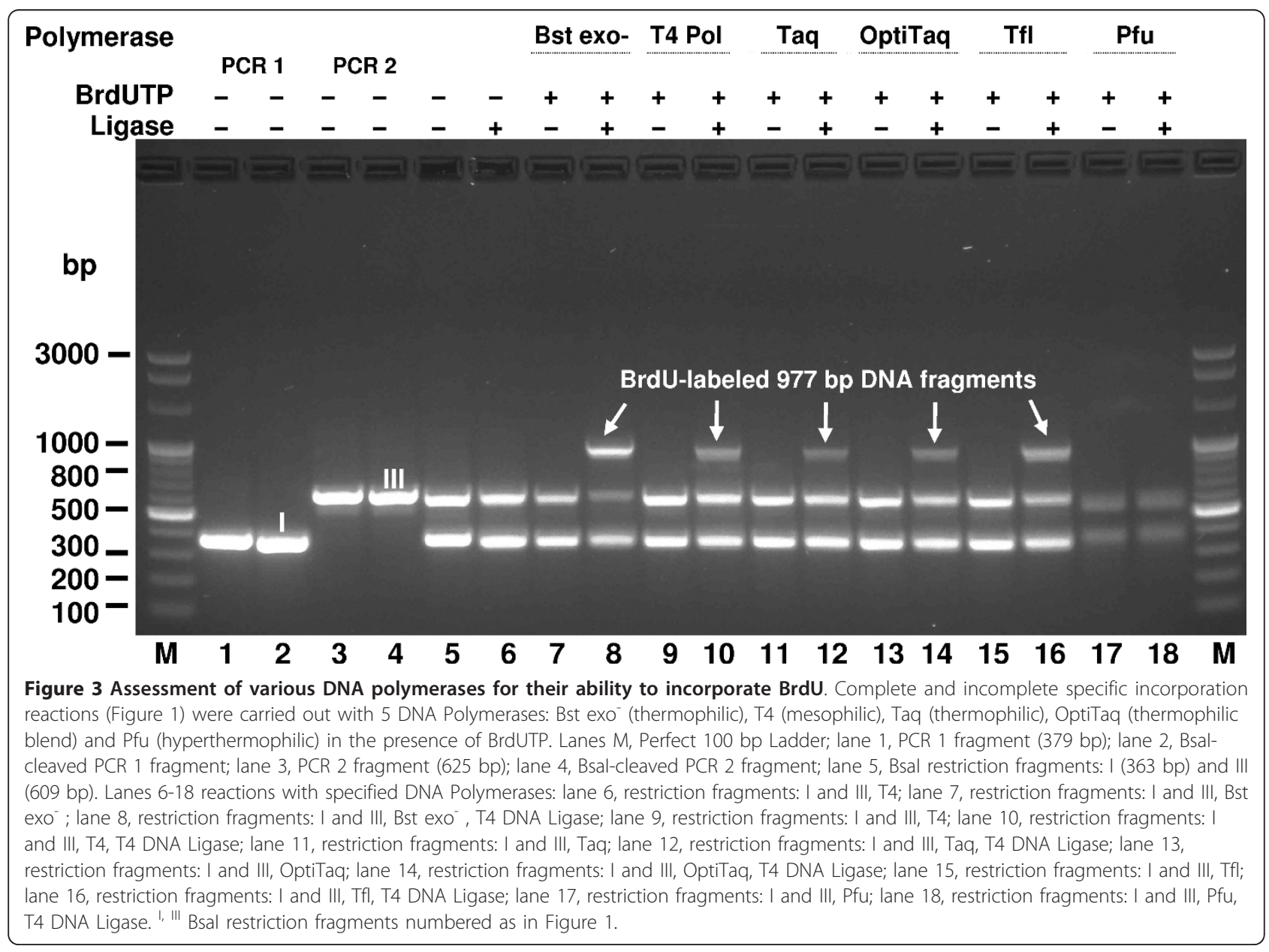


is capable of joining separate DNA molecules, containing unnatural bases within strand nicks, just $3 \mathrm{bp}$ apart. Clearly, DNA Ligase can utilize such unusual substrates. Moreover, we explored the possibility of increasing label density in DNA for the purpose of future studies of the enhanced sensitization of DNA and stimulation of double strand breakage following irradiation of neighboring BrdU residues in DNA: after incorporation, the modified Hal-modified residues are separated by only $3 \mathrm{bp}$.

The evaluation of polymerases shows clearly that the Bacillus stearothermophilus DNA Polymerase exo' Cterminal fragment exhibits the highest final yield of the generation hybrid 977 bp DNA molecule (Figure 3, lane 8 ), while the mesophilic T4 bacteriophage DNA Polymerase, Thermus aquaticus DNA Polymerase, proofreading Taq-Pfu blend DNA Polymerase (OptiTaq) and Thermus flavus DNA Polymerase exhibit a markedly lower reaction yield (Figure 3, lanes 10, 12, 14, 16). Pyrococcus furiosus proofreading DNA Polymerase does not result in any incorporation of BrdU; indeed, substantial DNA losses are observed (Figure 3, lane 18). The reaction is assayed for the presence of the final product, namely, the desired 977 bp band, and factors other than the ability to utilize BrdUTP are likely to play a role in the final yield. This may involve maintaining the integrity of 3-nt 5'-protruding DNA termini, owing to a lack of proofreading activities in the case of of Taq, Tfl and $\mathrm{T} 4$ polymerases. In view of the emergence of new thermostable polymerases, either discovered in nature or protein-engineered, further improvements of the method presented here are possible. Among the commercially available DNA polymerases a mutant of $P f u$ DNA polymerase that overcomes uracil stalling, allowing the polymerase to read through uracil located in the template strand or incorporated into the extending strand could be worth trying [39]. To further evaluate the universality of the method beyond just a single combination of fragments yielding a hybrid molecule, which increases the concentration of the label/per DNA molecule unit length for the purpose of HPLC analysis, additional 441 bp and 466 bp hybrid molecules were designed and constructed. The $441 \mathrm{bp}$ fragment was synthesized in the single BrdU residue integration mode and also in the double BrdU incorporation mode using Bst exo ${ }^{-}$DNA Polymerase (Figure 4). There was no difference in yield, regardless of whether double BrdU or single BrdU/single $\mathrm{T}$ residues were incorporated with a one bp precision (Figure 4, lane 3,5). These results were confirmed with the construction of the 466 bp hybrid molecule (Figure 5 , lane 9,10$)$. The reaction was closely monitored by the inclusion of a set of controls at key steps of the incorporation/assembly reaction (Figures 3, 4, 5). As a result of the use of non-phosphorylated primers and asymmetric cohesive ends, the synthesis reactions

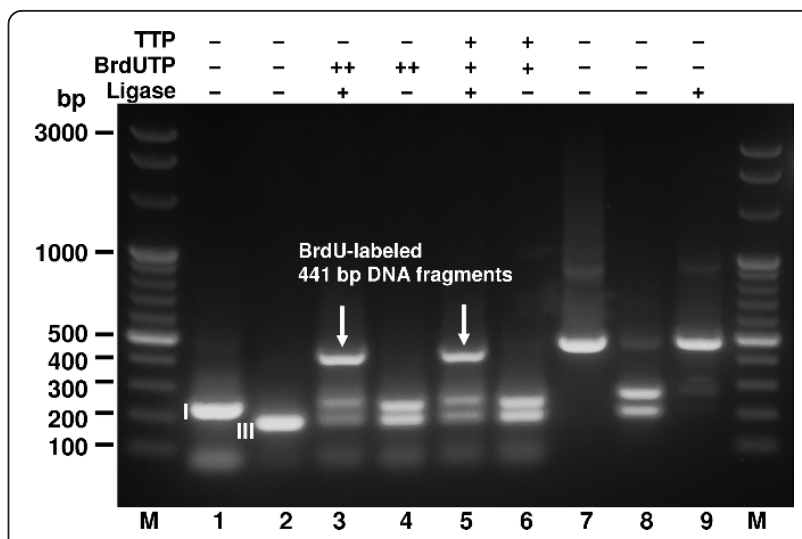

Figure 4 Incorporation of double and single BrdU residues by Bst exo- DNA Polymerase into the $\mathbf{4 4 1}$ bp hybrid molecule. Incorporation reactions using BrdUTP alone or in combination with dTTP were carried out with Bst exo DNA Polymerase. Lanes M, Perfect 100 bp Ladder (selected bands marked); lane 1, 260 bp Bsalcleaved PCR (restriction fragment I); lane 2, 208 bp Bsal-cleaved PCR (restriction fragment III); lane 3, BrdUTP-filled restriction fragments I and III, T4 DNA ligase; lane 4, BrdUTP-filled restriction fragments I and III; lane 5, dTTP-filled restriction fragment I and BrdUTP-filled restriction fragment III, T4 DNA ligase; lane 6, dTTP-filled restriction fragment I and BrdU-filled restriction fragment III. Lanes 7-9, controls of enzymes functional purity: lane 7, control PCR fragment with internal Bsal site; lane 8, Bsal-cleaved control PCR fragment; lane 9, Bsal-cleaved control PCR fragment after addition of T4 DNA Ligase; lane M, Perfect 100 bp Ladder. ", III Bsal restriction fragments numbered as in Figure 1.

depicted in Figures 3, 4 and 5 gave yields of the labeled molecules of over $50 \%$ with no by-products.

In order to simplify the analysis of labeled species, we have used 441, 466 and 977 bp model hybrid molecules. However, one should keep in mind, that the upper limit of labeled molecules length is much higher. With this method, extremely long DNA fragment can be obtained by means of a multiple assembly reaction $(n \times$ maximum PCR product length: $\mathrm{n} \times$ app. $50 \mathrm{~kb}$ ).

The method presented therefore seems to be uniquely suited to the construction of models for in vitro studies of anti-cancer therapy properties. Moreover, the method can be extended to protein-DNA interaction studies, by for example, the precise incorporation of modified bases into DNA-interacting protein recognition sites present on long DNA molecules.

\section{Determination of the presence of BrdU in hybrid DNA molecule}

The occurrence of bands corresponding to the BrdUlabeled hybrid DNA molecules in the gels (Figures 3, 4, and 5) is indirect proof that BrdU is incorporated into the ultimate product. Indeed, if the cohesive ends generated by BsaI are not filled with BrdUTP (or dTTP), no final product is obtained. However, when the partial filling of the cohesive ends precedes ligation, the formation 


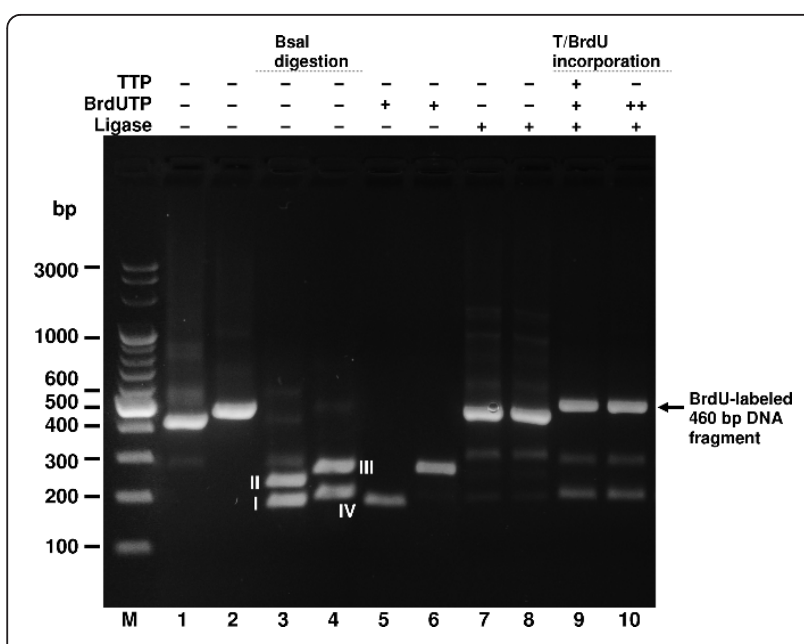

Figure 5 Incorporation of double and single BrdU residues by Bst exo- DNA Polymerase into the $\mathbf{4 6 6}$ bp hybrid molecule. Incorporation reactions using BrdUTP alone or in combination with dTTP were carried out with Bst exo DNA Polymerase. Lanes M, Perfect 100 bp Ladder (selected bands marked). Enzyme purity and reaction steps controls: lane 1, uncut 437 bp PCR fragment amplified from pGCN1 plasmid; lane 2, uncut 480 bp PCR fragment amplified from pGCN2 plasmid; lane 3, Bsal-cut 437 bp fragment; lane 4, Bsal-cut 480 bp fragment; lane 5, Bsal restriction fragment I (191 bp) filled in with BrdUTP isolated from agarose gel; lane 6, Bsal restriction fragment III (270 bp) filled in with BrdUTP isolated from agarose gel; lane 7, Bsal-cut 437 bp fragment, purified and backligated; lane 8, Bsal-cut 437 bp fragment, purified, incubated with Bst exo- DNA Pol without dNTPs and back-ligated. Incorporation reaction: lane 9, fragment I (191 bp) filled in with dTTP, ligated to BrdU-labeled fragment III (270 bp); lane 10, fragment I (191 bp) filled in with BrdUTP, ligated to BrdU-labeled fragment III (270 bp). ', III Bsal restriction fragments numbered as in Figure 1.

of a hybrid molecule is highly efficient (Figure 3, lane 8; Figure 4, lanes 3, 5; Figure 5, lanes 9, 10). Thus, one can infer that if the cohesive ends are partially filled with BrdUTP, BrdU has to be present in a hybrid DNA molecule. Although this indirect reasoning sounds convincing, one can also demonstrate directly that the BrdU molecule is present in the ligation product: namely, HPLC coupled to DNA digestion down to nucleosides is a suitable method for directly demonstrating the presence of BrdU in the synthesized material. Since the sensitivity of HPLC detection depends on the amount of a substance in the assayed sample, we chose the shortest fragment (of the three synthesized) labeled with two BrdU molecules to demonstrate the presence of 5-bromouridine. As a result of this choice we analyzed a digestion mixture in which the ratio of BrdU to the remaining nucleosides was the highest possible (taking into account the fact that three DNA fragments differing in the length and number of BrdU molecules were synthesized). Figure 6 shows two chromatograms: the upper panel (Figure 6A) corresponds to the HPLC separation of a mixture containing native nucleosides and 5-bromouridine; the lower panel (Figure 6B) shows the chromatogram obtained for the digested $441 \mathrm{bp}$ fragment containing two molecules of BrdU. The peak with the retention time of 26.9 min (Figure 6B) corresponds well to the BrdU signal $(27.1 \mathrm{~min}$ ) in the chromatogram of standards (Figure 6A). The small peak (see the absorbance scale) at $29.2 \mathrm{~min}$, as well as the peaks before the $\mathrm{dC}$ peak, between the $\mathrm{dC}$ and $\mathrm{dA}, \mathrm{dA}$ and $\mathrm{dG}$ and $\mathrm{dG}$ and $\mathrm{dT}$ peaks, are due to the digestion procedure, as indicated by the chromatogram obtained for the $441 \mathrm{bp}$ fragment, which does not contain the BrdU molecules (not shown). Additionally, by employing the peak areas of standards and the areas of the actual signals registered for the digested 441 bp labeled oligonucleotide, we were able to calculate its base content: the amount of BrdU turned out to be equal to 1.93, which is quite close to the theoretical value of 2. HPLC separation coupled to enzymatic digestion therefore demonstrates unequivocally that an oligonucleotide containing BrdU is indeed produced within our protocol.

\section{Conclusions}

$i$. A new method of incorporating labeled nucleotides at a precisely-predetermined location has been developed.

$i i$. The length of these enzymatically synthesized DNA molecules theoretically approaches a multiple of the maximum length obtainable in a single PCR reaction.

iii. The synthesis efficiency of the labeled molecules is better than $50 \%$ with no by-products

$i v$. This method is general and offers the possibility of preparing DNA duplexes labeled with a controlled number of Hal-Nbs as well as other labels.

$v$. A number of DNA polymerases have been tested for the incorporation of the haloderivative BrdU into DNA, indicating marked differences in the ability to distinguish modified dUTP from the non-modified precursor. The most efficient incorporation was obtained using Bst exo- DNA Polymerase.

$v i$. The presence of incorporated BrdU was proven by both ligation assay and HPLC analysis.

vii. The BrdU incorporation study is a contribution to the long-term goal of devising an anti-cancer therapy based on the in vivo incorporation of a haloderivative, followed by treatment with ionizing radiation.

\section{Methods}

\section{Bacterial strains, media and reagents}

Escherichia coli (E. coli) DH11S \{mcrA $\Delta\left[\right.$ mrr-hsdRMS $\left(\mathrm{r}_{\mathrm{K}-\text {, }}\right.$ $\left.\mathrm{m}_{\mathrm{K}+}\right)$-mcrBC] $\Delta($ lac-proAB) $\Delta($ recA1398) deoR, rpsL, srlthi, supE/F' proAB ${ }^{+}$lac $I^{Q} Z \Delta M 15$ \} (Life Technologies, Gaithersburg, MD, USA) was used as cloning host and for 


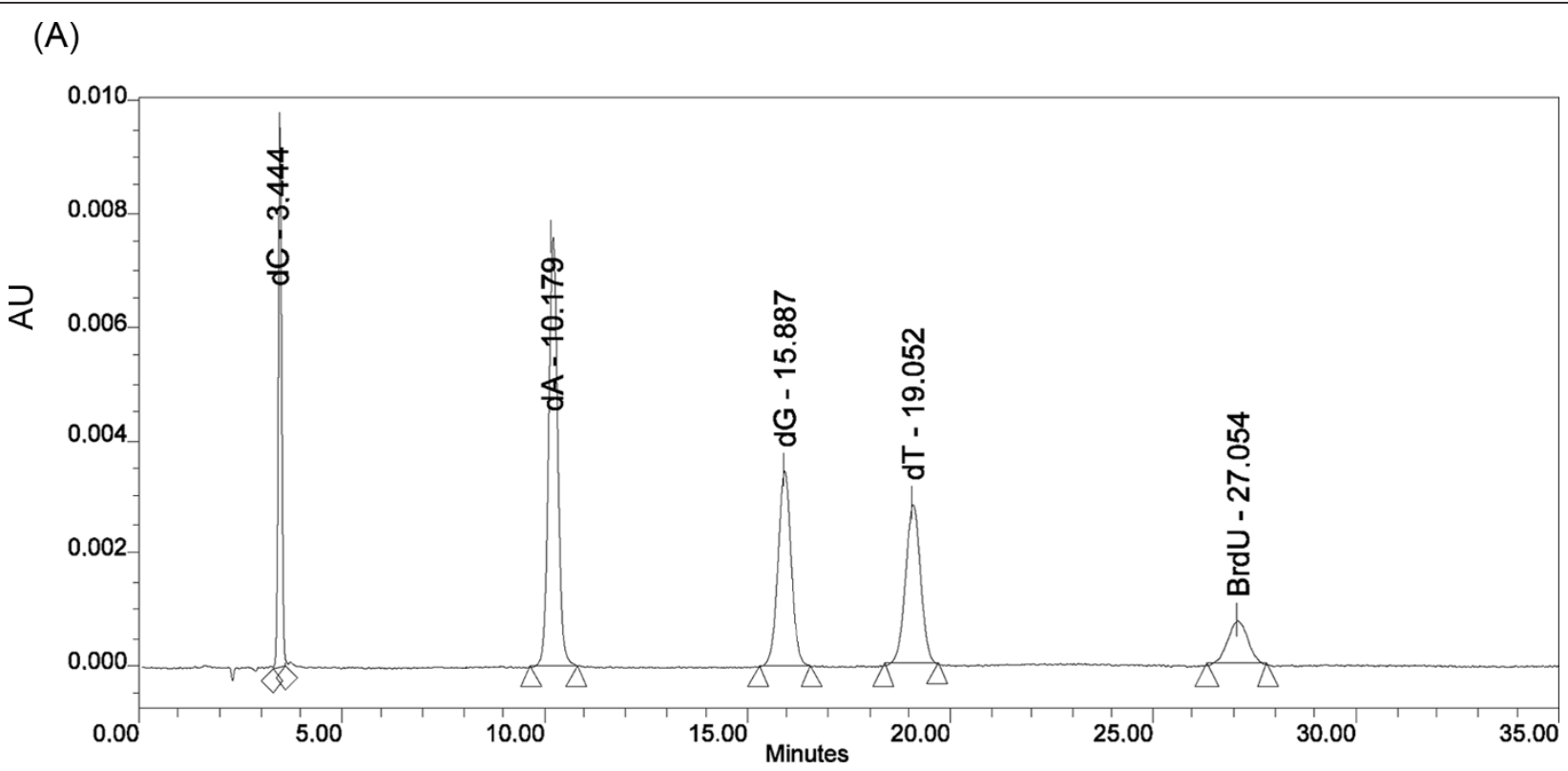

(B)

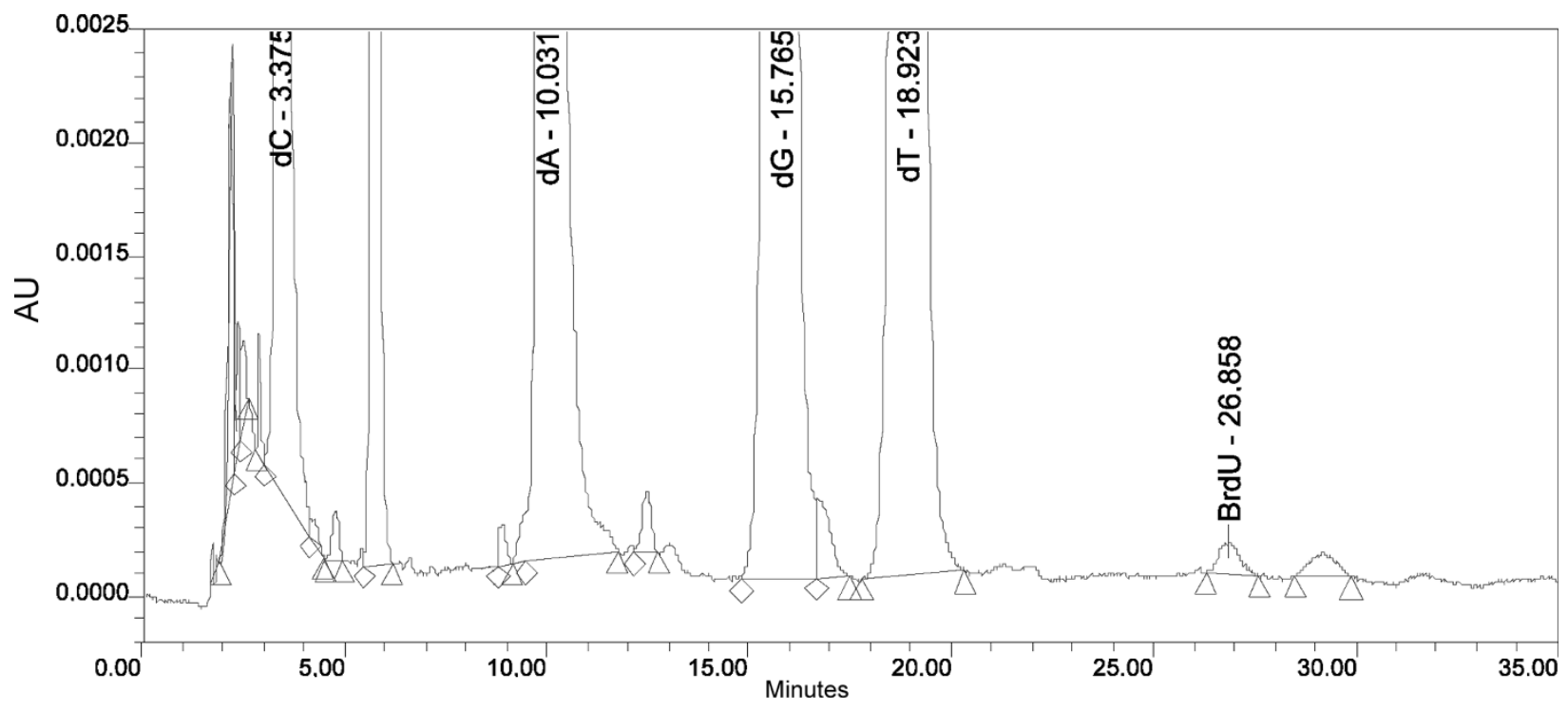

Figure 6 Chromatograms of the mixture of standards (A) and BrdU-labeled 441 bp oligomer after enzymatic digestion (B).

DNA propagation. Bacteria were grown in 2xYT medium [40] supplemented with chloramphenicol $(40 \mu \mathrm{g} / \mathrm{ml})$. BrdUTP and dNTPs were from Sigma-Aldrich (St. Louis, MO, USA). Difco media components were obtained from Becton-Dickinson (Franklin Lakes, NJ, USA), agarose GTG from FMC (Rockland, MA, USA), and the DNA purification kits, T4 DNA polymerase, Tfl DNA Polymerase, Taq DNA Polymerase, OptiTaq, GeneMatrix PCR/DNA Clean-Up Purification Kit and GeneMatrix Agarose-Out DNA Purification Kit were from EURx Ltd. (Gdansk, Poland). Bst DNA Polymerase large fragment exo-, pUC19 DNA, BsaI, NcoI and BspHI, T4 DNA ligase REase were from New England Biolabs (Ipswich, MA, USA). Pfu DNA Polymerase was from Agilent Technologies, Inc. (Santa Clara, CA, USA). Oligo and custom DNA sequencing were provided by Genomed (Warsaw, Poland). All other reagents were from Amresco (Solon, OH, USA) or SigmaAldrich, of the highest available purity.

\section{Construction of DNA molecules with precisely incorporated 5-BrdU}

To validate the universality of the proposed method, we used three different DNA constructs in vitro for the pinpoint incorporation of either double or single 5-BrdU. 


\section{7 bp hybrid DNA molecule}

The 977 bp hybrid DNA molecule was generated from two PCR products (379 bp and $625 \mathrm{bp}$ ) amplified from the pUC19 plasmid template. The 378 bp fragment was obtained using primer 1F: 5'-GTGGCGAAACCCGACAGGACT-3' and primer 1R:

5'-ATGAGTCATCCACCCATGAGACCACTTCAAGAACTC-3', whereas the primer 2F: 5'-GGATGTGCTGCAAGGCGATTA-3' and primer 2R:

5'-ATGAGTCATCCAGGGATGAGACCTCTGACTTGAGCG-3' were used for the $625 \mathrm{bp}$ fragment.

Incorporated BsaI sites are shown in bold and underlined. The hybrid molecule and PCR fragment sequences are available as additional files (Additional file 1).

\section{1 bp hybrid DNA molecule}

The 441 bp hybrid DNA molecule was generated from two PCR products (208 bp and $260 \mathrm{bp}$ ) amplified from the pUC19 plasmid template. The $208 \mathrm{bp}$ fragment was obtained using primer 3F: 5'-AGCGGTATCAGCTCACTCAAAGG-3' and primer 2R, whereas primer 4F: 5'- GAAGCGTGGCGCTTTCTCATAG -3' and primer $1 \mathrm{R}$ were used for the $260 \mathrm{bp}$ fragment. The hybrid molecule and PCR fragment sequences are available as additional files (Additional file 2).

The PCR reactions for generating $977 \mathrm{bp}$ and $441 \mathrm{bp}$ molecules were conducted in $50 \mu \mathrm{l}$ volume, $0.5 \mathrm{mM}$ of each primer, template $2.5 \mathrm{ng}, 60 \mu \mathrm{M}$ dNTPs, 2.5 units Taq Polymerase under thermocycling conditions: initial denaturation at $97^{\circ} \mathrm{C}$ for $2.5 \mathrm{~min}$, hot start at $80^{\circ} \mathrm{C}$, denaturation at $94^{\circ} \mathrm{C}$ for $30 \mathrm{sec}$, annealing at $53^{\circ} \mathrm{C}$ for $30 \mathrm{sec}$, extension at $72^{\circ} \mathrm{C}$ for $50 \mathrm{sec}$, final flush-in at $72^{\circ}$ $\mathrm{C}$ for $50 \mathrm{sec}, 40$ cycles. The amplification products were purified using the PCR/DNA Clean-Up Purification Kit.

\section{6 bp hybrid DNA molecule}

The 466 bp hybrid DNA molecule was generated from two PCR products (437 bp and $480 \mathrm{bp}$ ) amplified from two plasmid pRZ4737-derivatives. The templates used here (pGCN1 and pGNC2) were constructed by PCR and cloning for the purpose of this work as well as further studies on protein-directed Hal-NBs incorporation. The starting DNA for the construction was modified pRZ4737 plasmid vector $\left(\mathrm{Cm}^{\mathrm{R}}, \mathrm{P} 15 \mathrm{~A}\right.$ ori, f1 ori, $\mathrm{P}_{\mathrm{R}}$ promoter), originally obtained from Bill Resnikoff. Two PCR fragments of $162 \mathrm{bp}$ and $128 \mathrm{bp}$ were amplified from the vector using oligonucleotides containing long 5 '- overhangs and incorporating class-IIS REase BsaI and NcoI sites at each fragment 5 '-end (forward primers) and BspHI (reverse primer). Incorporated REase sites are shown in bold or underlined. The $162 \mathrm{bp}$ fragment was amplified with 5F primer: 5'- GCGCCATGGTCTCATCCCTGGATGACTCATTTCTTTTTTGTGC3' and 3R primer: 5' - AGCTCATGAACACCTCCTTAAAAAAAAAATGAGTCATCCATTATCACCG-3'. The 128 bp fragment was amplified with $6 \mathrm{~F}$ primer:
5'-CTTCCATGGTCTCATGGGAAATCTATCACCGCA-3'and the $3 R$ primer.

The $162 \mathrm{bp}$ and $128 \mathrm{bp}$ PCR products were cleaved with NcoI and BspHI and cloned into pRZ4737-derivative cleaved with BspHI. The BspHI and NcoI sites have compatible cohesive ends, which are not recleavable after cross-ligation. For further experiments plasmids were selected and designated pGCN1 and pGCN2. From these, construct upstream primers were used to amplify the $437 \mathrm{bp}$ and $480 \mathrm{bp}$ fragments for the labeling reaction. Primer 7F: 5'- AATTACCTATTGACGCAAGTCTCGAAGGCGACGTGCGTCC-3' was used as forward primer for the 437 bp product (template: pGCN1), and primer 8F: 5'-CATTAAATAAAGCACCAACGCCT-3' for the 480 bp product (template: pGCN2). Primer 4R: 5'-GAATTGTGAGCGGATAACAATTTCACACAG-3' was used as reverse primer for both fragments. Hybrid molecule and PCR fragment sequences are available as additional files (Additional file 3 ). The PCR reactions for the $437 \mathrm{bp}$ and $480 \mathrm{bp}$ fragments were conducted in 50 $\mu \mathrm{l}$ volume, $0.5 \mathrm{mM}$ each primer, template $2.5 \mathrm{ng}, 60 \mu \mathrm{M}$ dNTPs, 2.5 units Taq Polymerase under thermocycling conditions: initial denaturation at $94.5^{\circ} \mathrm{C}$ for $1.5 \mathrm{~min}$, hot start at $80^{\circ} \mathrm{C}$, denaturation at $94^{\circ} \mathrm{C}$ for $20 \mathrm{sec}$, annealing at $58^{\circ} \mathrm{C}$ for $30 \mathrm{sec}$, extension at $72^{\circ} \mathrm{C}$ for 40 sec, final flush-in at $72^{\circ} \mathrm{C}$ for $50 \mathrm{sec}, 40$ cycles. Amplification products were purified using the PCR/DNA Clean-Up Purification Kit.

\section{BrdU labeling reactions}

Purified PCR products were cleaved with Bsal (10 units per $1 \mu \mathrm{g} / \mathrm{DNA}$ ) for $1 \mathrm{~h}$ at $50^{\circ} \mathrm{C}$ as recommended by the manufacturer. Fill-in reactions were performed in $80 \mu \mathrm{l}$ reaction volume, containing $5 \mu \mathrm{g}$ DNA, 40 units of polymerase, $0.2 \mathrm{mM}$ BrdUTP, for $20 \mathrm{~min}$ at $70^{\circ} \mathrm{C}$ for thermophilic polymerases and $37^{\circ} \mathrm{C}$ for mesophilic polymerases in dedicated reaction buffers as recommended by the manufacturer. Ligation was carried out with 200 units of T4 DNA Ligase for $1.5 \mathrm{~h}$ at $16^{\circ} \mathrm{C}$ in $100 \mu \mathrm{l}$ reaction volume in the buffer recommended by the manufacturer.

\section{HPLC detection of incorporated 5-BrdU}

The purified DNA was digested to nucleosides prior to HPLC analysis by the simultaneous action of DNase I, snake venom phosphodiesterase (SVP) and bacterial alkaline phosphatase (BAP). 40 units of DNase I, 1 unit of BAP and 0.01 units of SVP were incubated with the purified DNA fragment in a final volume of $100 \mu \mathrm{l}$ in the following reaction buffer: Tris- $\mathrm{HCl}(\mathrm{pH} 8.5 ; 10$ $\mathrm{mM}), \mathrm{MgCl}_{2}(10 \mathrm{mM}), \mathrm{CaCl}_{2}(1 \mathrm{mM})$ and DTPA (diethylenetriamine pentaacetic acid, Sigma Aldrich) (40 $\mu \mathrm{M})$. The enzymatic digestion was performed at $37^{\circ} \mathrm{C}$ for $3 \mathrm{~h}$ ( $1 \mathrm{~h}$ with each enzyme, sequentially). After 
digestion, reaction mixtures were purified by centrifugation using Microcon centrifugal filter units with a YM-3 membrane, NMWCO $3 \mathrm{kDa}$ (Millipore). The resulting samples were dried down by rotary evaporation in a Speed-Vac Concentrator and dissolved in $60 \mu \mathrm{l}$ of ultrapure water. $20 \mu \mathrm{l}$ of the filtered sample was subjected to HPLC analysis, which was performed on a Waters ${ }^{\circledR}$ 600E Delivery System with a Waters ${ }^{\circledR} 2487$ Dual Lambda Absorbance detector set at $260 \mathrm{~nm}$ for monitoring the effluents. A Waters ${ }^{\circledR}$ Atlantis reverse-phase $\mathrm{dC}_{18}$ column $(4.6 \times 150 \mathrm{~mm} ; 5 \mu \mathrm{m}$ in particle size and $100 \mathrm{~L}$ in pore size) with a mobile phase consisting of deionized water, acetonitrile (Sigma-Aldrich, Poland) and $1 \%$ formic acid (POCH S.A., Poland) ( $\mathrm{pH} \mathrm{2.55;}$ $87.7: 2: 10.3, \mathrm{v} / \mathrm{v} / \mathrm{v})$ was used. The flow rate was set at 1 $\mathrm{ml} / \mathrm{min}$.

\section{Additional material}

Additional file 1: Sequence of the 977 hybrid DNA molecule. All DNA sequences are written in the 5'-3' direction. The DNA sequence of the $379 \mathrm{bp}$ PCR fragment is written in capital letters. The DNA sequence of the $625 \mathrm{bp} \mathrm{PCR}$ fragment is written in small letters. The positions that can be substituted with BrdU are marked in red and bold. The arrows show the Bsal cleavage points. The Bsal recognition sequences are placed in rectangular boxes. The Bsal restriction fragments forming the hybrid molecule are underlined. The DNA fragments removed following Bsal cleavage are in italics.

Additional file 2: Sequence of the $\mathbf{4 4 1}$ hybrid DNA molecule. All DNA sequences are written in the 5'-3' direction. The DNA sequence of the $260 \mathrm{bp} \mathrm{PCR}$ fragment is written in capital letters. The DNA sequence of the $208 \mathrm{bp}$ PCR fragment is written in small letters. The positions that can be substituted with BrdU are marked in red and bold. The arrows show the Bsal cleavage points. The Bsal recognition sequences are placed in rectangular boxes. The Bsal restriction fragments forming the hybrid molecule are underlined. The DNA fragments removed following Bsal cleavage are in italics.

Additional file 3: Sequence of the $\mathbf{4 4 6}$ hybrid DNA molecule. All DNA sequences are written in the 5'-3' direction. The DNA sequence of the $437 \mathrm{bp}$ PCR fragment is written in capital letters. The DNA sequence of the $480 \mathrm{bp}$ PCR fragment is written in small letters. The positions that can be substituted with BrdU are marked in red and bold. The arrows show the Bsal cleavage points. The Bsal recognition sequences are placed in rectangular boxes. The Bsal restriction fragments forming the hybrid molecule are underlined. The DNA fragments removed following Bsal cleavage are in italics.

\section{Acknowledgements}

The authors would like to express their gratitude to Piotr Storoniak for his valuable technical assistance. This work was supported by the Polish Ministry of Science and Higher Education under Grants Nos. N N204 023135 (J.R) and NR12-0070-06/2009 (P.S.).

\section{Authors' contributions}

IS performed most of the experiments, participated in the preparation of the figures and in the design and interpretation of all the experimental analyses. KP performed some experiments and participated in the design and interpretation of the experimental analyses. AZZS participated in the design and interpretation of the experimental analyses, the preparation of the figures and the writing of the manuscript. JJF prepared the cloned templates. PMS came up with the concept of the new method of nucleobase incorporation at a precisely pre-determined distance, participated in the design and interpretation of experiments and drafted the manuscript. JR participated in the design and interpretation of the experiments, conceived the project, coordinated its execution and drafted the manuscript. All authors read and approved the final manuscript.

Received: 31 March 2011 Accepted: 24 August 2011

Published: 24 August 2011

\section{References}

1. Szybalski W, Kim SC, Hasan N, Podhaiska AJ: Class- IIS restriction enzymesa review. Gene 1991, 100:13-26, Erratum in: Gene 1991, 20, 109(1):169.

2. Kim SC, Podhajska AJ, Szybalski W: Cleaving DNA at any predetermined site with adapter-primers and class-IIS restriction enzymes. Science 1988, 240(4851):504-506.

3. Kim SC, Skowron PM, Szybalski W: Structural requirements for Fokl-DNA interaction and oligodeoxyribonucleotide-instructed cleavage. J Mol Biol 1996, 258(4):638-649.

4. Koob M, Grimes E, Szybalski W: Conferring new specificity upon restriction endonucleases by combining repressor-operator interaction and methylation. Gene 1988, 74(1):165-167.

5. Skowron PM, Harasimowicz R, Rutkowska SM: GCN4 eukaryotic transcription factor/Fokl endonuclease mediated 'Achilles' Heel Cleavage': quantitative study of protein-DNA interaction. Gene 1996, 170:1-8.

6. Lee JH, Skowron PM, Rutkowska SM, Hong SS, Kim SC: Sequential amplification of cloned DNA as tandem multimers using class-IIS restriction endonucleases. Genet Anal 1996, 13:139-145.

7. Kim YG, Chandrasegaran S: Chimeric restriction endonuclease. Proc Natl Acad Sci USA 1994, 91(3):883-887.

8. Sugiyama H, Fuijmoto K, Saito I: Preferential $\mathrm{Cl}^{\prime}$ hydrogen abstraction by an uracilyl radical in a DNA-RNA hybrid. Tetrahedron Lett 1997, 38(46):8057-8060.

9. Kawai K, Saito I, Sugiyama H: Conformation-dependent photochemistry of 5- halouracil-containing DNA: Stereospecific 2'-hydroxylation of deoxyribose in Z-form DNA. J Am Chem Soc 1999, 121(6):1391-1392.

10. Oyoshi T, Wang AH-J, Sugiyama H: Photoreactivity of 5-iodouracilcontaining DNA-Sso7d complex in solution: the protein-induced DNA kink causes intrastrand hydrogen abstraction from the 5-methyl of thymine at the 5' side. J Am Chem Soc 2002, 124(4):579-584.

11. Dietz TM, Koch TH: Photochemical reduction of 5-bromouracil by cysteine derivatives and coupling of 5-bromouracil to cysteine derivatives. Photochem Photobiol 1989, 49(2):121-129.

12. Blatter EE, Ebright $Y W$, Ebright RH: Identification of an amino acid-base contact in the GCN4-DNA complex by bromouracil-mediated photocrosslinking. Nature 1992, 359(6396):650-652.

13. Willis MC, Hicke BJ, Uhlenbeck OC, Cech TR, Koch TH: Photocrosslinking of 5-iodouracil-substituted RNA and DNA to proteins. Science 1993, 262(5137):1255-1257.

14. Jansen $K B$, Atkinson $B L$, Willis $M C$, Koch $T H$, Gold $L$ : Using in vitro selection to direct the covalent attachment of human immunodeficiency virus type 1 Rev protein to high-affinity RNA ligands. Proc Natl Acad Sci USA 1995, 92(26):12220-12224.

15. Beach C, Fuciarelli AF, Zimbrick JD: Electron migration along 5bromouracil-substituted DNA irradiated in solution and in cells. Radiat Res 1994, 137(3):385-93.

16. Rivera E, Schuler RH: Intermediates in the reduction of 5-halouracils by $e_{a q}==^{-1}$. J Phys Chem 1983, 87(20):3966-3971.

17. Cecchini S, Girouard S, Huels MA, Sanche L, Hunting DJ: Interstrand crosslinks: a new type of gamma-ray damage in bromodeoxyuridinesubstituted DNA. Biochemistry 2005, 44(6):1932-1940.

18. Zeng $Y$, Wang $Y$ : Facile formation of an intrastrand cross-link lesion between cytosine and guanine upon pyrex-filtered UV light irradiation of $\mathrm{d}((\mathrm{Br}) \mathrm{CG})$ and duplex DNA containing 5-bromocytosine. J Am Chem Soc 2004, 126(21):6552-6553.

19. Zhang $Q$, Wang Y: Generation of 5-(2'-deoxycytidyl)methyl radical and the formation of intrastrand cross-link lesions in oligodeoxyribonucleotides. Nucleic Acid Res 2005, 33(5):1593-1603.

20. Hong H, Wang Y: Formation of intrastrand cross-link products between cytosine and adenine from UV irradiation of $\mathrm{d}((\mathrm{Br}) \mathrm{CA})$ and duplex DNA containing a 5-bromocytosine. J Am Chem Soc 2005, 127(40):13969-13977. 
21. Fornace AJ Jr, Dobson PP, Kinsella TJ: Enhancement of radiation damage in cellular DNA following unifilar substitution with iododeoxyuridine. Int J Radiat Oncol Biol Phys 1990, 18(4):873-878.

22. Franken NA, Van Bree CV, Kipp JB, Barendsen GW: Modification of potentially lethal damage in irradiated Chinese hamster V79 cells after incorporation of halogenated pyrimidines. Int J Radiat Biol 1997, 72(1):101-109.

23. Watanabe $T$, Bando $T, X u Y$, Tashiro $R$, Sugiyama $H$ : Efficient generation of 2'-deoxyuridin-5-yl at 5'-(G/C)AA(X)U(X)U-3' (X = Br, I) sequences in duplex DNA under UV irradiation. J Am Chem Soc 2005, 127(1):44-45.

24. Fujimoto K, Ikeda Y, Saito I: Direct strand cleavage via furanyladenine formation in anaerobic photoirradiation of 5-bromouracil-containing oligonucleotides. Tetrahedron Lett 2000, 41(33):6455-6459.

25. Cook GP, Greenberg MM: A Novel Mechanism for the Formation of Direct Strand Breaks upon Anaerobic Photolysis of Duplex DNA Containing 5Bromodeoxyuridine. J Am Chem Soc 1996, 118(42):10025-10030.

26. Cook GP, Chen T, Koppisch AT, Greenberg MM: The effects of secondary structure and $\mathrm{O} 2$ on the formation of direct strand breaks upon UV irradiation of 5-bromodeoxyuridine-containing oligonucleotides. Chem Biol 1999, 6(7):451-459.

27. Sugiyama H, Tsutsumi $Y$, Saito I: Highly sequence-selective photoreaction of 5-bromouracil-containing deoxyhexanucleotides. J Am Chem So 1990, 112(18):6720-6721.

28. Fuijmoto K, Sugiyjama H, Saito I: Sequence dependent photoreduction of 5-bromouracil-contaning oligonucleotides via electron transfer. Tetrahedron Lett 1998, 39(15):2137-2140.

29. Chen T, Cook GP, Koppisch AT, Greenberg MM: Investigation of the origin of the sequence selectivityfor the 5-halo-2'-deoxyuridine sensitization of DANN to damage by UV-irradiation. J Am Chem Soc 2000, 122:3861-3866.

30. Szybalski W: X-ray sensitization by halopyrimidines. Cancer Chemoter Rep 1974, 58(4):539-557.

31. Ling LL, Ward JF: Radiosensitization of Chinese hamster V79 cells by bromodeoxyuridine substitution of thymidine: enhancement of radiation-induced toxicity and DNA strand break production by monofilar and bifilar substitution. Radiat Res 1990, 121(1):76-83.

32. Prados MD, Scott C, Sandler H, Buckner JC, Phillips T, Schultz C, Urtasun R, Davis R, Guttin P, Cascino TL, Greenberg HS, Curran WJ: A phase 3 randomized study of radiotherapy plus procarbazine, CCNU, and vincristine (PCV) with or without BUdR for the treatment of anaplastic astrocytoma: a preliminary report of RTOG 9404. Int J Radiat Oncol Biol Phys 1999, 5(5):1109-1115.

33. Erikson RL, Szybalski W: Molecular radiobiology of human cell lines. v. comparative radiosensitizing properties of 5-halodeoxycytidines and 5halodeoxyuridines. Radiat Res 1963, 20:252-262.

34. Frenken NA, Van Bree C, Veltmaat MA, Rodermond HM, Haveman J, Barensen GW: Radiosensitization by bromodeoxyuridine and hyperthermia: analysis of linear and quadratic parameters of radiation survival curves of two human tumor cell lines. J Radiat Res (Tokyo) 2001, 42(2):179-190.

35. Matsutani M, Kohno T, Nagashima T, Nagayama I, Matsuda T, Hoshino T, Sano K: Clinical trial of intravenous infusion of bromodeoxyuridine (BUdR) for radiosensitization of malignant brain tumors. Radiat Med 1988, 6(1):33-39.

36. Peters JP, Becker NA, Rueter EM, Bajzer Z, Kahn JD, Maher LJ: Quantitative methods for measuring DNA flexibility in vitro and in vivo. 3rd Methods Enzymol 2011, 488:287-335.

37. Roberts RJ, Vincze T, Posfai J, Macelis D: REBASE - enzymes and genes for DNA restriction and modification. Nucleic Acids Res 2010, 38:D234-D236.

38. Pósfai G, Szybalski W: Increasing the Fokl cleavage specificity from 5 to 7 base pairs by two-step methylation. Nucleic Acids Res 1988, 16(13):6245.

39. Fogg MJ, Pearl LH, Connolly BA: Structural basis for uracil recognition by archaeal family B DNA polymerases. Nat Struct Biol 2002, 9(12):922-927.

40. Sambrook J, Fitsch EF, Maniatis T: Molecular Cloning: A Laboratory Manual Cold Spring Harbor, Cold Spring Harbor Press; 1989.

doi:10.1186/1471-2091-12-47

Cite this article as: Sobolewski et al.: Enzymatic synthesis of long double-stranded DNA labeled with haloderivatives of nucleobases in a precisely pre-determined sequence. BMC Biochemistry 2011 12:47.

\section{Submit your next manuscript to BioMed Central and take full advantage of:}

- Convenient online submission

- Thorough peer review

- No space constraints or color figure charges

- Immediate publication on acceptance

- Inclusion in PubMed, CAS, Scopus and Google Scholar

- Research which is freely available for redistribution

Submit your manuscript at www.biomedcentral.com/submit
C Biomed Central 